\title{
Cholesterol-Lowering Effect of Allicin on Hypercholesterolemic ICR Mice
}

\author{
Yin Lu, ${ }^{1}$ Zhuojin He, ${ }^{2}$ Xiuying Shen, ${ }^{3}$ Xiaolu Xu, ${ }^{1}$ Jie Fan, ${ }^{4}$ Shaohua Wu, ${ }^{5}$ and Deyong Zhang ${ }^{1}$ \\ ${ }^{1}$ College of Biological and Environmental Engineering, Zhejiang Shuren University, Hangzhou 310015, China \\ ${ }^{2}$ Institute of Bioengineering, Zhejiang Academy of Medical Science, Hangzhou 310013, China \\ ${ }^{3}$ School of Biological and Chemical Engineering, Zhejiang University of Science and Technology, Hangzhou 310023, China \\ ${ }^{4}$ Department of Biology, Shaoxing No.1 High School, Shengli West Road 1199, Yuecheng District, Shaoxing 312000, China \\ ${ }^{5}$ Cardiovascular Department, Integrated Chinese and Western Medicine Hospital, Hangzhou Shangcheng District, \\ Hangzhou 310008, China
}

Correspondence should be addressed to Yin Lu, luyin@yahoo.cn

Received 13 March 2012; Accepted 12 June 2012

Academic Editor: Michal Wozniak

Copyright ( 92012 Yin Lu et al. This is an open access article distributed under the Creative Commons Attribution License, which permits unrestricted use, distribution, and reproduction in any medium, provided the original work is properly cited.

\begin{abstract}
Allicin was discussed as an active compound with regard to the beneficial effects of garlic in atherosclerosis. The aim of this study was to investigate the cholesterol-lowering properties of allicin. In order to examine its effects on hypercholesterolemia in male ICR mice, this compound with doses of 5,10 , or $20 \mathrm{mg} / \mathrm{kg}$ body weight was given orally daily for 12 weeks. Changes in body weight and daily food intake were measured regularly during the experimental period. Final contents of serum cholesterol, triglyceride, glucose, and hepatic cholesterol storage were determined. Following a 12-week experimental period, the body weights of allicinfed mice were less than those of control mice on a high-cholesterol diet by $38.24 \pm 7.94 \%(P<0.0001)$ with $5 \mathrm{mg} / \mathrm{kg}$ allicin, $39.28 \pm 5.03 \%(P<0.0001)$ with $10 \mathrm{mg} / \mathrm{kg}$ allicin, and $41.18 \pm 5.00 \%(P<0.0001)$ with $20 \mathrm{mg} / \mathrm{kg}$ allicin, respectively. A decrease in daily food consumption was also noted in most of the treated animals. Meanwhile, allicin showed a favorable effect in reducing blood cholesterol, triglycerides, and glucose levels and caused a significant decrease in lowering the hepatic cholesterol storage. Accordingly, both in vivo and in vitro results demonstrated a potential value of allicin as a pronounced cholesterol-lowering candidate, providing protection against the onset of atherosclerosis.
\end{abstract}

\section{Introduction}

Atherosclerosis (AS) is one of the major risk factors in the development of hypertension and cardiovascular diseases. It is the narrowing or occlusion of the arteries by plaque, which consists of cholesterol, platelets, monocyte/macrophages, calcium, aggregating proteins, and other substances. Morbidity of AS-induced coronary heart disease (CHD) gradually elevates annually due to the improvement of life standard and the change of lifestyle in recent years. However, the mechanism of the onset and development of atherosclerotic lesions are not completely understood until now. Many complicated factors interaction and interrelated biological processes contribute to AS. Among these, high plasma levels of low-density lipoprotein (LDL), especially its oxidized form (ox-LDL), and activation of the renin-angiotensin system
(RAS) are considered to be the key influencing factor of the generation and development of AS [1,2].

Recently, various natural products have emerged as active ingredients effective in controlling of AS $[3,4]$. The medicinal use of garlic (Allium sativum) has been known since the Ancient Egyptian era. For centuries, garlic was used for treating high blood pressure in China and Japan. Its reported beneficial effects include detoxification, antioxidation, antifungal, antibacterial activity, tumour suppression, and prevention of heart disease [5]. In relation to heart disease, a major part of these publications deals with the beneficial effect on the cardiovascular system, mainly related to AS. Garlic has been shown to alter blood lipids [6], decrease blood coagulability [7], and inhibit cell proliferation $[8,9]$. Furthermore, garlic has been found to act as an antihypertensive agent [10] and has been officially recognized 
as the treatment of hypertension by the Japanese Food and Drug Administration [11]. Although the data available today suggest that garlic contains biologically active compounds which are beneficial in cardiovascular disease like AS, the question about the active principles and their mechanism of action is still not settled $[5,12]$.

Allicin ((R,S)-diallyldisulfid-S-oxide), one of the sulfur compounds from garlic, is formed by the action of the enzyme alliinase on alliin. It possesses antioxidant activity and is shown to cause a variety of actions potentially useful for human health [12]. Allicin exhibits hypolipidemic, antiplatelet, and procirculatory effects. Moreover, it demonstrates antibacterial, anticancer, and chemopreventive activities.

The background and the fact mentioned above focused our interest on the question of whether the known constituent of processed garlic, allicin, which is discussed as an active component with regard to the beneficial effects of garlic preparation, has an effect on AS. Most previous studies used various garlic preparations in which allicin levels were not well defined. In the present study, we investigated the body weight, feed intake, and lipid profile in plasma, following hepatic cholesterol storage changes in the experimental model of hypercholesterolemic ICR mice, to evaluate whether application of a known amount of pure allicin has a beneficial effect on formation of fatty streaks (AS) and blood lipid levels in mice.

\section{Results}

2.1. Changes in Body Weight and Feed Intake. The oral administration of allicin to hypercholesterolemic ICR mice for 12 weeks resulted in a significant reduction in the bodyweight gain in a dose-dependent manner (Figure 1). The body weight increased from $19.70 \pm 2.23 \mathrm{~g}, 20.07 \pm 0.44 \mathrm{~g}$, and $19.22 \pm 1.67 \mathrm{~g}$ at the start of the study to $31.93 \pm 3.01 \mathrm{~g}, 31.39 \pm$ $2.42 \mathrm{~g}$, and $30.41 \pm 3.98 \mathrm{~g}$ at the termination in the groups administered with doses of 5, 10, and $20 \mathrm{mg} / \mathrm{kg}$ allicin, respectively. Three test groups yielded reductions in body weight gain of $38.24 \pm 7.94 \%(P<0.0001), 39.28 \pm 5.03 \%$ $(P<0.0001)$, and $41.18 \pm 5.00 \%(P<0.0001)$, respectively, as compared to the high-cholesterol control. The high-cholesterol diet alone yielded no difference in body weight gain when compared to the normal group (fed with a regular chow diet), indicating that the supplementation of cholesterol itself had no appreciable effect on body weight gain.

A similar decline was seen in the daily food consumption of allicin treatment (Table 1). In contrast to a previous report [13], our observations demonstrated a significant decrease in food consumption in a dose-dependent manner. This tendency was most pronounced in the first two weeks of the test. From that point on, it steadily regressed toward the control value until the end of the test period except in the $20 \mathrm{mg} / \mathrm{kg}$ allicin group, where the food intake remained somewhat lower than in the control group throughout the experiment. At the 12th week of the test, the relative mean feed intake was $82.0 \pm 4.7 \%, 80.1 \pm 4.3 \%$ and $67.7 \pm 2.4 \%$, of the high cholesterol control in 5, 10, and $20 \mathrm{mg} / \mathrm{kg}$ allicinadministered groups, respectively.

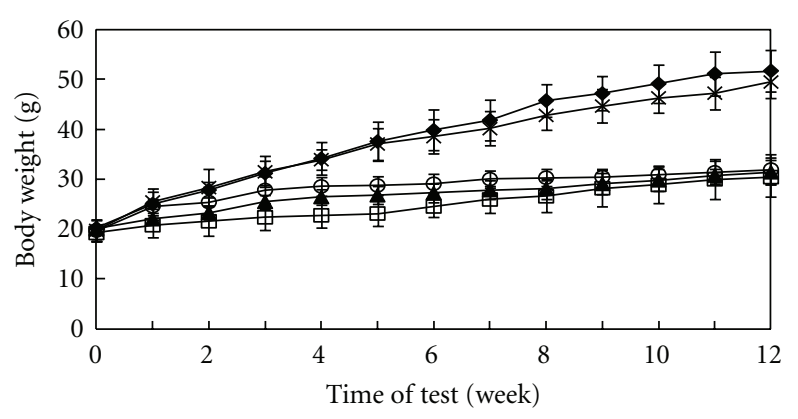

Figure 1: Body weight changes $(n=6)$. Allicin was administered with doses (p.o.) of $0(\checkmark), 5(\bigcirc), 10(\mathbf{\Delta})$, and $20(\square) \mathrm{mg} / \mathrm{kg}$, respectively; the high cholesterol diet was fed throughout the test. The regular chow diet group $(x)$ received no allicin treatment. The data are expressed as mean \pm S.D. and are considered to be significantly different at $P<0.05$ by the unpaired Student's $t$ test; $P<0.01$ (from the 2 th week of test) in $5 \mathrm{mg} / \mathrm{kg}$ allicin group; $P<0.0001$ (from 1 th week of test) in 10 and $20 \mathrm{mg} / \mathrm{kg}$ allicin groups.

2.2. Biochemical Analysis of the Serum. Biochemical parameters in mouse plasma and lipoproteins at the end of the study period were shown in Table 2. As shown in the results, the high-cholesterol diet group obtained an elevated TC, TG, GLU, and LDL-C, but a decreased HDL$\mathrm{C}$, suggesting an effective induction of hypercholesterolemia by supplementation of cholesterol in the diet, was effectively established in ICR mice. The allicin administration in doses of 5,10 , and $20 \mathrm{mg} / \mathrm{kg}$ lowered the elevated TC to $75.94 \%, 56.92 \%$, and $64.77 \%$ of high-cholesterol control, respectively. A similar decrease was seen in LDL-C level; the concentrations of which declined to $57.92 \%, 56.83 \%$, and $43.72 \%$ of control, respectively. The concentrations of $\mathrm{HDL}-\mathrm{C}$ in all the allicin-treated animals, however, revealed no significant differences except $5 \mathrm{mg} / \mathrm{kg}$ group. Table 2 also showed that allicin administration lowered the elevated TG values to $63.03 \sim 89.57 \%$ and GLU levels to $57.53 \sim 62.00 \%$ of high-cholesterol control, respectively.

2.3. Atherosclerotic Pathological Changes in the Liver. High cholesterol diet stimulation could promote hyperlipidemia, aggravated pathological changes of the liver, and even developed AS in the animals. Based on the results, the morphology of hepatic cells in allicin-administered groups showed obvious pathological changes in a dose-dependent manner compared with that of the high-cholesterol control group (Figure 2). The lipid accumulation in hepatic cells in allicin administered groups became smaller and less than those of mice given by PBS as a placebo. However, there were no significant changes accompanied with fatty alteration and accretion of cells' volume in the normal group, compared to the mice at 5 weeks of age.

\section{Discussion}

In recent years, remarkable progress has been made in the prevention and treatment of AS. Atherosclerotic diseases such as ischemic heart disease, stroke, and peripheral arterial 
TABLE 1: Food intake efficiency during allicin administration $(n=6)$.

\begin{tabular}{lcccrc}
\hline Week & 1 & 2 & 3 & 11 & 12 \\
\hline Control $^{\mathrm{d}}$ & $100 \pm 2.1$ & $100 \pm 3.7$ & $100 \pm 1.4$ & $100 \pm 4.9$ & $100 \pm 6.0$ \\
$5 \mathrm{mg} / \mathrm{kg}$ allicin & & $90.1 \pm 4.2$ & $80.0 \pm 2.3^{\mathrm{a}}$ & $70.7 \pm 5.9^{\mathrm{a}}$ & $82.0 \pm 4.7$ \\
$10 \mathrm{mg} / \mathrm{kg}$ allicin $^{\mathrm{e}}$ & $54.3 \pm 0.5^{\mathrm{b}}$ & $74.2 \pm 11.7^{\mathrm{a}}$ & $68.9 \pm 1.6^{\mathrm{b}}$ & $80.5 \pm 3.1^{\mathrm{a}}$ & $80.1 \pm 4.3$ \\
$20 \mathrm{mg} / \mathrm{kg}$ allicin $^{\mathrm{e}}$ & $42.0 \pm 1.3^{\mathrm{c}}$ & $65.5 \pm 5.7^{\mathrm{b}}$ & $53.0 \pm 3.3^{\mathrm{b}}$ & $65.4 \pm 3.2^{\mathrm{b}}$ & $67.7 \pm 2.4^{\mathrm{a}}$ \\
Normal (regular diet) $^{\mathrm{e}}$ & $89.9 \pm 12.8^{\mathrm{a}}$ & $85.6 \pm 2.6^{\mathrm{a}}$ & $82.3 \pm 4.0^{\mathrm{a}}$ & $93.4 \pm 14.8$ & $82.7 \pm 15.9$ \\
\hline
\end{tabular}

The data are mean \pm S.D. and significantly different at ${ }^{\mathrm{a}} P<0.05,{ }^{\mathrm{b}} P<0.01$, and ${ }^{\mathrm{c}} P<0.001$ by the unpaired Student's $t$-test.

${ }^{\mathrm{d}}$ The high cholesterol control group, $200 \mu \mathrm{L}$ PBS (pH 7.4) was served instead of allicin as a negative control.

${ }^{\mathrm{e}}$ The results are expressed as $\%$ of the high cholesterol control.

TABLE 2: Serum parameters after 12-week allicin administration $(n=6, \mathrm{mM})$.

\begin{tabular}{lccccc}
\hline Parameter & $5 \mathrm{mg} / \mathrm{kg}$ & $\begin{array}{c}10 \mathrm{mg} / \mathrm{kg} \\
\text { High-cholesterol diet (allicin administered) }\end{array}$ & Control $^{\mathrm{c}}$ & Normal (regular diet) $^{20 \mathrm{mg} / \mathrm{kg}}$ & $32.99 \pm 0.55$ \\
TC & $43.91 \pm 4.21^{\mathrm{b}}$ & $32.91 \pm 1.34^{\mathrm{b}}$ & $37.45 \pm 0.80^{\mathrm{b}}$ & $57.82 \pm 3.51^{\mathrm{b}}$ & $1.04 \pm 0.23$ \\
TG & $1.66 \pm 0.34^{\mathrm{a}}$ & $1.33 \pm 0.11^{\mathrm{b}}$ & $1.89 \pm 0.19^{\mathrm{b}}$ & $2.11 \pm 0.35^{\mathrm{b}}$ & $8.38 \pm 0.75$ \\
GLU & $8.73 \pm 0.49$ & $8.22 \pm 1.52$ & $8.10 \pm 0.14$ & $14.08 \pm 3.16^{\mathrm{b}}$ & $1.94 \pm 0.22$ \\
HDL-C & $1.25 \pm 0.20^{\mathrm{a}}$ & $1.71 \pm 0.59$ & $1.60 \pm 0.45$ & $1.61 \pm 0.16$ & $1.57 \pm 0.43$ \\
LDL-C & $1.06 \pm 0.52^{\mathrm{a}}$ & $1.04 \pm 0.22^{\mathrm{a}}$ & $0.80 \pm 0.15^{\mathrm{a}}$ & $1.83 \pm 0.50$ & \\
\hline
\end{tabular}

The data are mean \pm S.D. and significantly different at ${ }^{\mathrm{a}} P<0.05$ and ${ }^{\mathrm{b}} P<0.01$ by the unpaired Student's $t$-test.

TC: total cholesterol, TG: triglyceride, GLU: plasma glucose, HDL-C: high-density lipoprotein cholesterol, LDL-C: low-density lipoprotein cholesterol.

${ }^{\mathrm{c}}$ The high cholesterol control group, $200 \mu \mathrm{L}$ PBS (pH 7.4) was served instead of allicin as a negative control.

disease are associated with high serum cholesterol, male gender, age, hypertension, cigarette smoking, diabetes, and so forth. Reduction in the concentration of blood lipids, especially cholesterol, is a major goal in several primary and secondary prevention initiatives. Therefore, the approaches to the prevention and treatment of atherosclerotic diseases are based primarily on the reduction of risk factors or rather modifiable factors such as hyperlipidemia, hypertension, and diabetes. This approach can be regarded as indirect antiatherosclerotic therapy.

Several studies have suggested that garlic may have beneficial effects on plasma cholesterol levels [14-16], while other studies found no influence [15-18]. We suggest that the composition and quantity of sulfur components of different protocol designs of garlic preparations used in various studies and the different mouse models used could account in part for the inconsistent findings. The pharmacological activities of garlic are attributed to the thiosulfinate compounds, of which allicin is approximately $75 \%$ [17]. Therefore, garlic antiatherosclerotic properties are mainly attributed to allicin. The use of pure allicin to study the atheroprotective effect of garlic is reasonable.

In the present study, by using pure allicin, we could investigate the effect of a well-defined component of garlic on AS and to seek for possible mechanisms of its antiatherogenic activity. Authors of many studies have shown the relationship between high-cholesterol levels, especially HDL-C and LDLC, and the development of AS [18]. The high-cholesterol diet could induce a rise in blood cholesterol level to more physiologic levels, for which the rise became unphysiologic [19]. We chose not to use the transgenic mouse models of AS, although they resemble human AS better, because these models have a very strong phenotype and therefore might not be the best model for the proof of the current hypothesis. Results here demonstrated that the daily administration of pure allicin to ICR mice had a beneficial effect on the lipid profile, causing a distinct decrease in the serum TC, LDL-C, and accordingly a certain amount of decrease in the level of TG and GLU. The reduction in LDL-C was more pronounced than that of any other type of cholesterol. Since the concentration of HDL-C was not significantly changed, the cholesterol-lowering effect was in fact exclusively attributed to the decline of LDL-C, making the most characteristic changes involved in cholesterol modulation by allicin. Similar results that allicin exerted a beneficial effect on the lipid profile in hyperlipidemic rabbits had been previously reported [20].

On the other hand, the results also showed a significant decrease in lowering the hepatic cholesterol storage as compared with the controls. The lipid accumulation in hepatic cells has decreased as well, suggesting that allicin alleviated liver stress related to hypercholesterolemia and thus was advantageous to prevent from becoming a fatty liver.

Moreover, food consumption in allicin-treated animals showed a remarkable decline in a dose-dependent manner. Food consumption can play a role in cholesterol homeostasis as an independent influential factor. Since the restriction in food intake is also correlative to blood cholesterol reduction, it is quite possible that allicin has affected cholesterol homeostasis by a simple but efficient way of food intake suppression, as well as the change of body weight. And the actions of the cholesterol lowering presented in this paper would endow more nutritional and therapeutic value with allicin.

In summary, the present study confirmed and extended the understanding that allicin may beneficially affect the risk factors for AS-hyperlipidemia and attribute to lower 


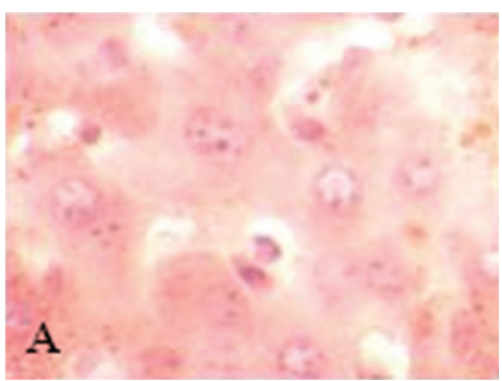

(a)

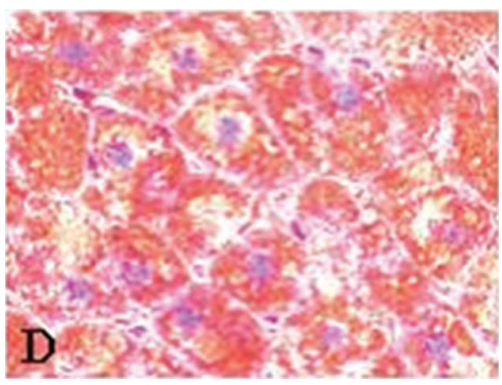

(d)

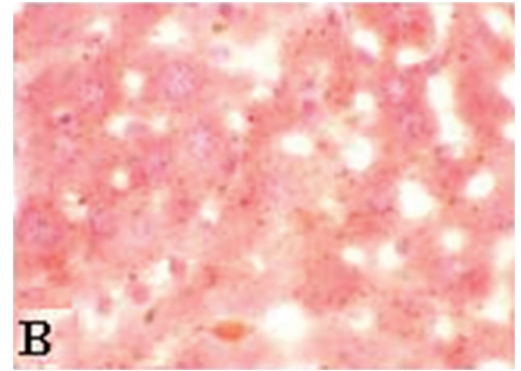

(b)

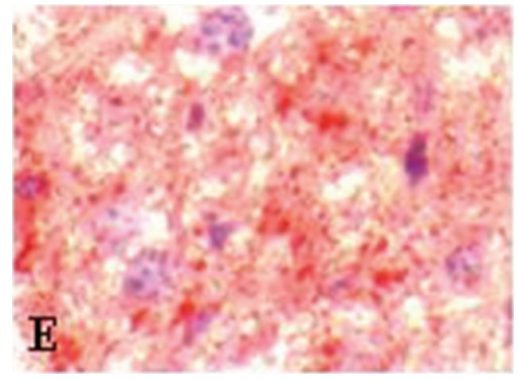

(e)

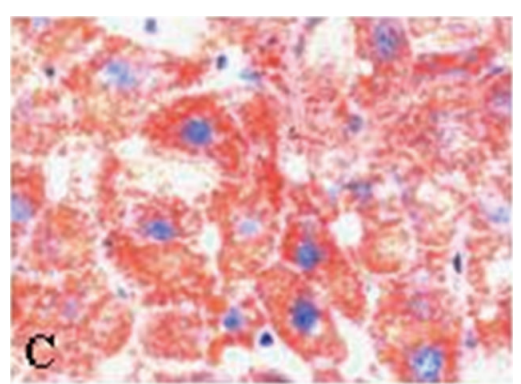

(c)

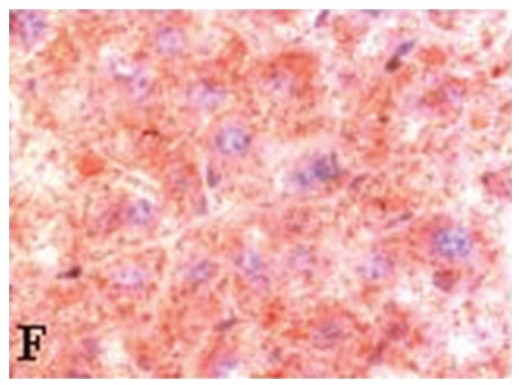

(f)

FIgURe 2: Photomicrographs of the section surface of livers stained with Oil Red O. (a) ICR mice (5 weeks age), fed with high cholesterol diet for one week before test; (b) normal group (17 weeks age), fed with a regular chow diet for 12 weeks; (c) high cholesterol control group (17 weeks age), fed with high cholesterol diet plus PBS for 12 weeks; (d) $5 \mathrm{mg} / \mathrm{kg}$ allicin administered group (17 weeks age), fed with high cholesterol diet for 12 weeks; (e) $10 \mathrm{mg} / \mathrm{kg}$ allicin administered group (17 weeks age), fed with high cholesterol diet for $12 \mathrm{weeks}$; (f) $20 \mathrm{mg} / \mathrm{kg}$ allicin administered group (17 weeks age), fed with high cholesterol diet for 12 weeks. Magnification: $\times 400$.

the hepatic cholesterol storage. Thus, the active component allicin could potentially provide protection against the onset of AS. However, it is noteworthy that allicin is very reactive and rapidly converted to its metabolites [21], which may limit its biological activity. Further studies to elucidate the exact mechanism and the molecular basis of action of allicin on various animal species and in particular on humans are required.

\section{Subjects and Methods}

4.1. Preparation of Allicin. Allicin, synthesized compound with purity more than 95\%, was obtained from Lichtwer Pharma GmbH (Germany) and dissolved in phosphatebuffered saline (PBS). The solution was stored in dark at $4^{\circ} \mathrm{C}$ until use (not more than 3 months). The chemical stability of allicin was assessed using HPLC and quantitatively determined at particular time intervals.

\subsection{Oral Administration of Allicin to Hypercholesterolemic} ICR Mice. Male ICR mice ( 3 weeks, $10 \pm 2 \mathrm{~g}$ ) were provided by the Animal Center, Academy of Chinese Traditional Medicine, Zhejiang, China. All mice were raised in a 12/12hour light-dark cycle room with controlled temperature (21$23^{\circ} \mathrm{C}$ ) and humidity (50-60\%). The mice were fed two kinds of diet. The atherogenic high-cholesterol diet contained $15.75 \%$ fat $(43 \%$ saturated fat) and $1.25 \%$ cholesterol (TD88137; Harlan). The regular chow diet consisted of $4.5 \%$ fat by weight $(0.02 \%$ cholesterol) (TD19519; Koffolk).
To minimize oxidation, the diets were stored in the dark at $4^{\circ} \mathrm{C}$ until use. The animals were given ad libitum with the regular chow diet and tap water for one week prior to any experiment. Then after the mice had been fed with highcholesterol diet for one week, only those with over $200 \mathrm{mg} / \mathrm{dL}$ of blood cholesterol were selected for use in the experiment.

Some sources recommend that allicin should be used in high doses for medicinal purposes [13, 22]. In our preliminary study, three means of administration, intraperitoneal (ip), intravenous (iv) and oral (po) were tested for allicin. For oral administration for the dose-range experiment, higher concentrations of allicin-administered op $(25 \mathrm{mg} / \mathrm{kg} /$ day $)$ caused discomfort to the animals and were discontinued. And a regimen of $2 \mathrm{mg} / \mathrm{kg} /$ day was ineffective. We therefore tested a modified version of the allicin po regimen. Twentyfour selected mice were divided into four groups $(n=6)$ by randomization, three allicin test groups and one highcholesterol control group. To the three test groups, $200 \mu \mathrm{L}$ allicin solution in PBS was orally administered to correspond to 5,10 , or $20 \mathrm{mg}$ allicin/ $\mathrm{kg}$ body weight once per day for a period of 12 weeks (the amount of allicin administered had been found to be safe in a preliminary study). To the highcholesterol control group, $200 \mu \mathrm{L}$ PBS (pH 7.4) was served instead of allicin as a negative control. All the above animals were provided with the high-cholesterol diet throughout the animal test. A normal group $(n=6)$ fed with a regular chow diet was used for comparison and was supplied with the same volume of PBS (pH 7.4) instead of allicin. The mice were observed at least twice a day for clinical abnormalities. 
4.3. Body Weight and Feed Intake. During the 12-week treatment, all mice appeared healthy and there was no evidence of toxicity. The body weight was recorded once weekly and feed intake daily. The feed intake efficiency in each group was evaluated by monitoring the feed consumption (g) in each cage for two consecutive days and was calculated per animal per day basis.

4.4. Collection of the Serum and Determination of Serum Parameters. The animals were kept at the above regimen and fed the diet as indicated above for a period of 12 weeks. At the end of the experimental period, the mice were sacrificed by cervical dislocation after 16 hours of fasting. Blood samples were collected by cardiac puncture and allowed to clot for $2 \mathrm{~h}$ at room temperature, followed by centrifugation at $3500 \mathrm{xg}$ for $10 \mathrm{~min}$ to obtain the serum. It was separated and stored at $-80^{\circ} \mathrm{C}$ until analysis. The levels of total cholesterol (TC), triglycerides (TG), glucose (GLU), high-density lipoprotein cholesterol (HDL-C), and low-density lipoprotein cholesterol (LDL-C) were measured in the serum of mice using an automated enzymatic technique (Boehringer Mannheim, Mannheim, Germany) [23].

4.5. Assessment of AS in the Liver. The livers were also removed at the time of sacrifice for evaluating the formation of fatty streaks (AS). After thoroughly cleaning the peripheral fat, the livers were excised, weighed, and placed into individual vials containing physiologic saline $(0.9 \%)$ and iced for about $2 \mathrm{~h}$. The livers were prepared for sectioning by removing the lower portion with the plan of sectioning. Each liver was placed in a $15 \mathrm{~mm} \times 15 \mathrm{~mm} \times 15 \mathrm{~mm}$ cryomold mount containing octreotide (OCT, Miles Inc.) compound embedding medium, and then frozen with a cork back on liquid nitrogen. The embedded livers were kept in a freezer at $-80^{\circ} \mathrm{C}$ until they were sectioned. Each liver was sectioned into $5 \mu \mathrm{m}$ thick serial sections using a cryostat. Once the desired area had been located, 15 serial sections were obtained and stained with Oil Red O (Sigma, USA). These sections were viewed by light microscopy and were photographed using a Zeiss Photomicroscopy III camera.

4.6. Statistical Analysis. Each experiment was performed in triplicate and repeated at least twice. Values were expressed as means \pm standard deviations (S.D.). Differences in mean values between groups were analyzed by a one-way analysis of variance and Dunnett's test. $P<0.05$ was considered statistically significant.

\section{Acknowledgments}

This research was jointly supported by the Natural Scientific Foundation of Zhejiang Province (LY12C03009, Y5110135, and Y5110130). And the authors thank the Academy of Chinese Traditional Medicine, Zhejiang, China, for their technical assistance. And the authors are grateful to Professor Xiaodong Zheng of the Department of Food Science and Nutrition, Zhejiang University, China, for her valuable assistance.

\section{References}

[1] D. Steinberg, S. Parthasarathy, T. E. Carew, J. C. Khoo, and J. L. Witztum, "Beyond cholesterol: modifications of low-density lipoprotein that increase its atherogenicity," The New England Journal of Medicine, vol. 320, no. 14, pp. 915-924, 1989.

[2] H. Esterbauer, J. Gebicki, H. Puhl, and G. Jurgens, "The role of lipid peroxidation and antioxidants in oxidative modification of LDL," Free Radical Biology and Medicine, vol. 13, no. 4, pp. 341-390, 1992.

[3] K. S. Bramlett, K. A. Houck, K. M. Borchert et al., "A natural product ligand of the oxysterol receptor, liver X receptor," Journal of Pharmacology and Experimental Therapeutics, vol. 307, no. 1, pp. 291-296, 2003.

[4] L. K. Han, Y. N. Zheng, B. J. Xu, H. Okuda, and Y. Kimura, "Saponins from Platycodi radix ameliorate high fat dietinduced obesity in mice," Journal of Nutrition, vol. 132, no. 8, pp. 2241-2245, 2002.

[5] K. C. Agarwal, "Therapeutic actions of garlic constituents," Medicinal Research Reviews, vol. 16, pp. 111-124, 1996.

[6] S. Phelps and W. S. Harris, "Garlic supplementation and lipoprotein oxidation susceptibility," Lipids, vol. 28, no. 5, pp. 475-477, 1993.

[7] C. Legnani, M. Frascaro, G. Guazzaloca, S. Ludovici, G. Cesarano, and S. Coccheri, "Effects of a dried garlic preparation on fibrinolysis and platelet aggregation in healthy subjects," Arzneimittel-Forschung/Drug Research, vol. 43, no. 2, pp. 119-122, 1993.

[8] E. S. Lee, M. Steiner, and R. Lin, "Thioallyl compounds: potent inhibitors of cell proliferation," Biochimica et Biophysica Acta, vol. 1221, no. 1, pp. 73-77, 1994.

[9] A. N. Orekhov, V. V. Tertov, I. A. Sobenin, and E. M. Pivovarova, "Direct anti-atherosclerosis-related effects of garlic," Annals of Medicine, vol. 27, no. 1, pp. 63-65, 1995.

[10] K. K. Al-Qattan, M. A. Alnaqeeb, and M. Ali, "The antihypertensive effect of garlic (Allium sativum) in the rat two- kidneyone-clip Goldblatt model," Journal of Ethnopharmacology, vol. 66, no. 2, pp. 217-222, 1999.

[11] S. Bolton, G. Null, and W. M. Troetel, "The medical uses of garlic_fact and fiction," American Pharmacy, vol. NS22, no. 8, pp. 40-43, 1982.

[12] H. D. Reuter, H. P. Koch, and L. D. Lawson, "Therapeutic effects and applications of garlic and its preparations," in The Science and Therapeutic Application of Allium Sativum and Related Species, H. P. Koch and L. Lawson LDGarlic, Eds., Williams and Wilkins, Baltimore, Md, USA, 1996.

[13] D. Abramovitz, S. Gavri, D. Harats et al., "Allicin-induced decrease in formation of fatty streaks (atherosclerosis) in mice fed a cholesterol-rich diet," Coronary Artery Disease, vol. 10, no. 7, pp. 515-519, 1999.

[14] S. K. Banerjee and S. K. Maulik, "Effect of garlic on cardiovascular disorders: a review," Nutrition Journal, vol. 1, article 1, pp. 1-14, 2002.

[15] L. D. Brace, "Cardiovascular benefits of garlic (Allium sativum L.)," Journal of Cardiovascular Nursing, vol. 16, no. 4, pp. 3349, 2002.

[16] M. J. Kwon, Y. S. Song, M. S. Choi, S. J. Park, K. S. Jeong, and Y. O. Song, "Cholesteryl ester transfer protein activity and atherogenic parameters in rabbits supplemented with cholesterol and garlic powder," Life Sciences, vol. 72, no. 26, pp. $2953-$ 2964, 2003.

[17] S. M. S. Espirito Santo, B. J. M. van Vlijmen, R. Buytenhek et al., "Well-characterized garlic-derived materials are not 
hypolipidemic in $\mathrm{APOE}^{*} 3$-Leiden transgenic mice," Journal of Nutrition, vol. 134, no. 6, pp. 1500-1503, 2004.

[18] G. F. Watts, B. Lewis, J. N. H. Brunt et al., "Effects on coronary artery disease of lipid-lowering diet, or diet plus cholestyramine, in the St Thomas' Atherosclerosis Regression Study (STARS)," The Lancet, vol. 339, no. 8793, pp. 563-569, 1992.

[19] B. Paigen, A. Morrow, and C. Brandon, "Variation in susceptibility to atherosclerosis among inbred strains of mice," Atherosclerosis, vol. 57, no. 1, pp. 65-73, 1985.

[20] S. Eilat, Y. Oestraicher, A. Rabinkov et al., "Alteration of lipid profile in hyperlipidemic rabbits by allicin, an active constituent of garlic," Coronary Artery Disease, vol. 6, no. 12, pp. 985-990, 1995.

[21] A. Gonen, D. Harats, A. Rabinkov et al., "The antiatherogenic effect of allicin: possible mode of action," Pathobiology, vol. 72, no. 6, pp. 325-334, 2005.

[22] A. Coppi, M. Cabinian, D. Mirelman, and P. Sinnis, "Antimalarial activity of allicin, a biologically active compound from garlic cloves," Antimicrobial Agents and Chemotherapy, vol. 50, no. 5, pp. 1731-1737, 2006.

[23] J. George, A. Afek, B. Gilburd et al., "Hyperimmunization of apo-E-deficient mice with homologous malondialdehyde lowdensity lipoprotein suppresses early atherogenesis," Atherosclerosis, vol. 138, no. 1, pp. 147-152, 1998. 


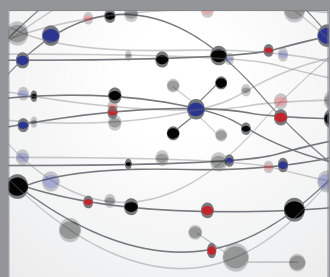

The Scientific World Journal
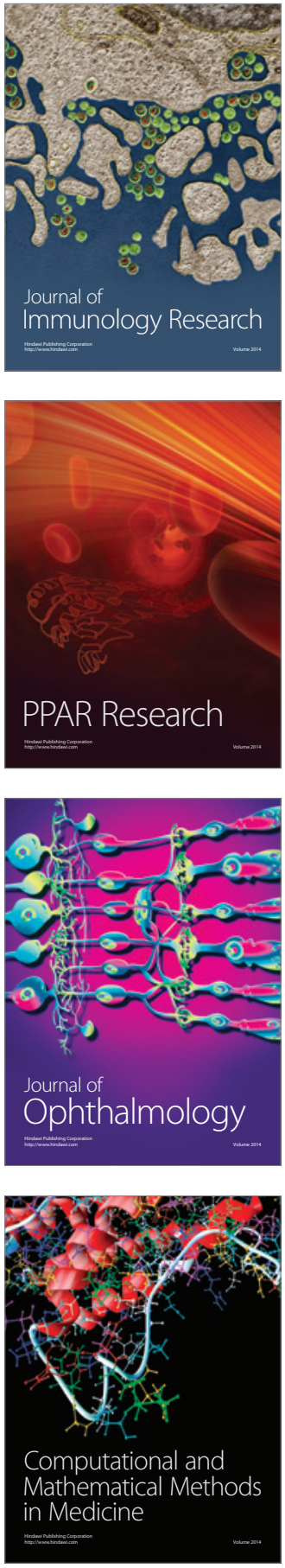

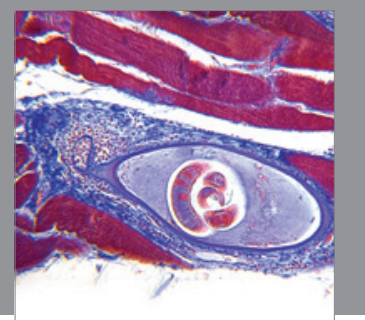

Gastroenterology

Research and Practice
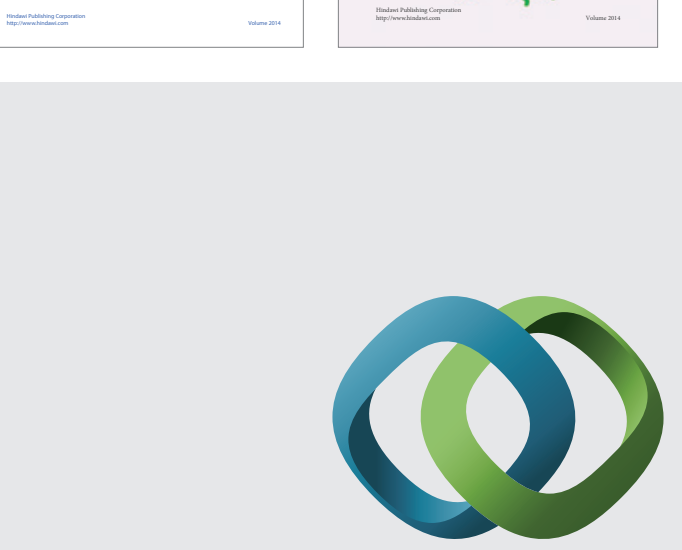

\section{Hindawi}

Submit your manuscripts at

http://www.hindawi.com
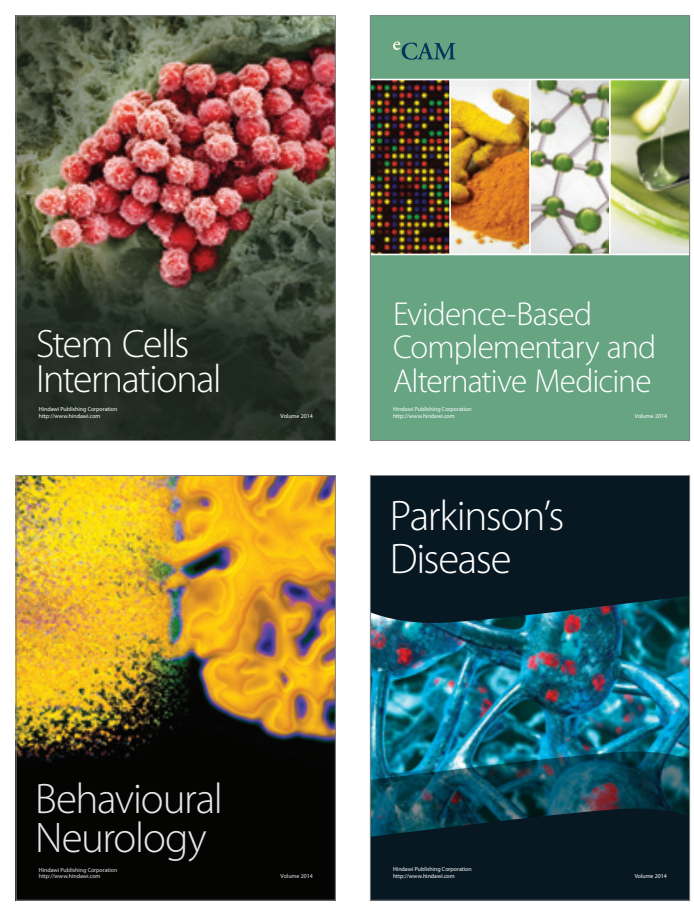

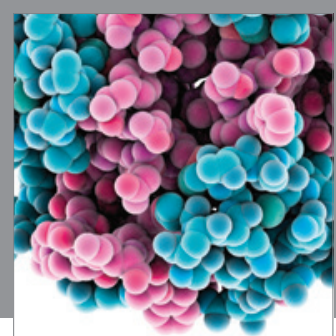

Journal of
Diabetes Research

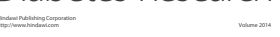

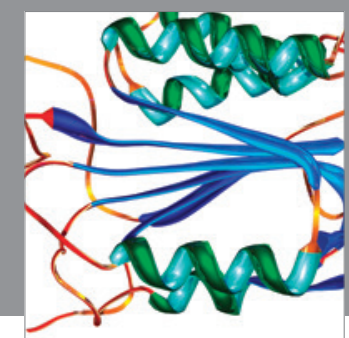

Disease Markers
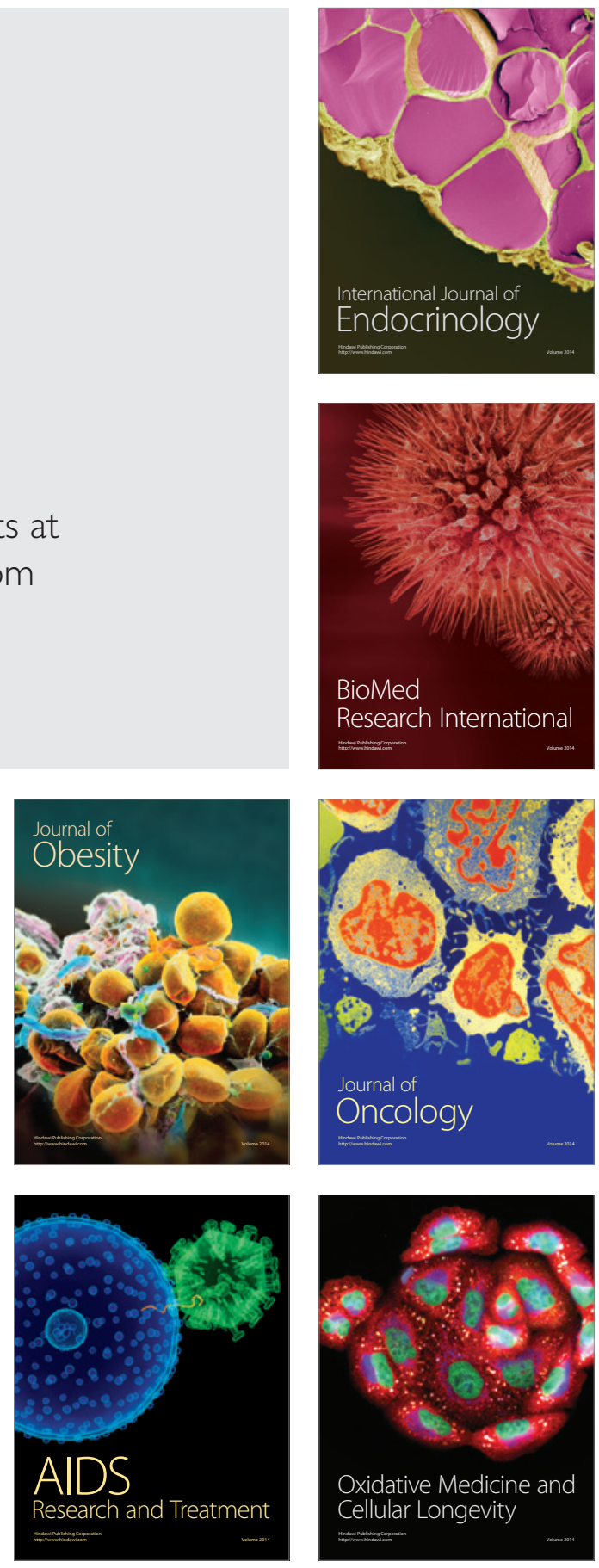